Originally published as:

Mätz-Rensing, K., Stahl-Hennig, C., Kramski, M., Pauli, G., Ellerbrok, H., Kaup, F.-J.

The Pathology of Experimental Poxvirus Infection in Common Marmosets (Callithrix jacchus): Further Characterization of a New Primate Model for Orthopoxvirus Infections (2012) Journal of Comparative Pathology, 146 (2-3), pp. 230-242.

DOI: $10.1016 /$ j.jcpa.2011.06.003

This is an author manuscript.

The definitive version is available at: http://www.sciencedirect.com/ 


\title{
The Pathology of Experimental Poxvirus Infection in Common Marmosets (Callithrix jacchus): Further Characterization of a New Primate Model for Orthopoxvirus Infections
}

\author{
K. Mätz-Rensing*' C. Stahl-Hennig*, M. Kramski ${ }^{\dagger}{ }^{\dagger}$, G. Pauli ${ }^{\dagger}$, H. Ellerbrok ${ }^{\dagger}$, F.-J. Kaup* \\ * German Primate Center (DPZ), Göttingen, Germany, ${ }^{\dagger}$ Robert Koch Institute, Berlin, Germany and \\ ${ }^{\ddagger}$ Department of Microbiology and Immunology, University of Melbourne, Melbourne, Australia
}

\begin{abstract}
Summary
Zoonotic orthopoxvirus (OPV) can induce severe disease in man and the virus has potential for use in bioterrorism. New vaccines and therapeutics against OPV infections must be tested in animal models. The aim of this study was to characterize the clinical course and pathology of a new OPV isolate, calpox virus, which is infectious in marmosets. Infection experiments were performed with 28 common marmosets (Callithrix jacchus) exposed to different challenge doses of calpox virus by the intravenous, oropharyngeal and intranasal (IN) routes. The median marmoset IN infectious dose corresponded to $8.3 \times 10^{2}$ plaque forming units of calpox virus. Infected animals developed reproducible clinical signs and died within 4-15 days post infection. Characteristic pox-like lesions developed in affected organs, particularly in the skin, mucous membranes, lymph nodes, liver and spleen. Calpox virus disease progression and pathological findings in the common marmoset appear to be consistent with lethal OPV infections in man and in other non-human primate (NHP) models. IN inoculation with low virus doses mimics the natural route of the human variola virus infection. Thus, the marmoset model of calpox virus infection can be considered to be relevant to investigation of the mechanisms of OPV pathogenesis and pathology and for the evaluation of new vaccines and antiviral therapies.
\end{abstract}

\section{Introduction}

In addition to possible intentional release of variola virus (VARV) as a biological weapon, the increasing zoonotic potential of orthopoxviruses (OPVs) has recently become of concern (LeDuc and Jahrling, 2001). Both cowpox virus (CPXV) ( [Chantrey et al., 1999] and [Campe et al., 2009]) and monkeypox virus (MPXV) have crossed the species barrier to man ( [DiGiulio and Eckburg, 2004] and [Parker et al., 2007]). Naturally occurring OPV diseases are of growing concern because the number of people with vaccinia virus (VACV)-induced immunity is declining. MPXV is endemic in Western and Central Africa and outbreaks of human MPXV resemble smallpox infection (Nalca et al., 2005). More recently, an outbreak of human MPXV infection was reported in the Midwest of the USA (Centers for Disease Control and Prevention, 2003). CPXV infections are presently limited to Europe and Asia. Human CPXV infections acquired from pet rats or other pet or zoo animals are reported in increasing number ( [Baxby et al., 1979], [Baxby et al., 1994], [Pilaski et al., 1986], [Vorou et al., 2008] and [Campe et al., 2009]) and the number of animal species susceptible to CPXV is increasing similarly. Field and experimental studies have indicated that CPXV has a broad host range and maintains a reservoir in wild rodents. CPXV is endemic in bank voles (Myodes glareolus) and wood mice (Apodemus sylvaticus), which serve as the main reservoirs (Begon et al.., 1999). Furthermore, the virus is often isolated from domestic cats, which should be regarded as a potential source of infection in urban areas ( [Baxby et al., 1979], [Chantrey et al., 1999] and [Hazel et al., 2000]). The majority of human CPXV and MPXV infections have a mild course, leading to localized, often selflimiting skin lesions with low morbidity (Campe et al., 2009). However, hospitalization of CPXVinfected individuals is reported and immunosuppressed individuals are at particular risk of developing 
severe complications, including disseminated infection and death ( [Eis-Hübinger et al., 1990] and [Czerny et al., 1991]).

Waning herd immunity because of discontinuation of smallpox vaccination is probably contributing to the increased incidence of OPV infections in man, particularly in younger age groups, with more severe courses of clinical infection (Kurth et al., 2009). In addition, increasing global travel and importation of exotic animal species from OPV-endemic areas increases the risk of OPV transmission. The development of new vaccines with low side-effects and efficient antiviral drugs is needed to counteract the risk of zoonotic OPV infections. Research into therapeutic agents for prevention and treatment of OPV infections requires adequate animal models to investigate the efficacy and safety of new vaccines and antiviral compounds. The two-animal rule of the US Food and Drug Administration states that efficacy and safety studies must be performed in more than one animal species, one of which should preferably be non-human primates (NHPs). Currently, the most common animal models for studying OPV infections are murine models of ectromelia virus (ECTV) and VACV infections. The best species in which to study human disease, virus pathology, vaccines and antiviral compounds are NHPs. At present two NHP models are established. These are MPXV infection of cynomolgus macaques (Macaca fascicularis) (Hooper et al., 2004) and rhesus macaques (Macaca mulatta) (Stittelaar et al., 2005) as well as VARV infection of cynomolgus macaques (Jahrling et al., 2004).

A major limitation of all macaque models is that very high infectious doses must be administered, primarily by intravenous (IV) administration in order to induce severe disease. For the cynomolgus macaque model of VARV infection, $10^{9}$ plaque forming units (pfu) given IV are required to cause typical smallpox signs with a mortality of at least $33 \%$ (Jahrling et al., 2004). The rhesus macaque model of MPXV infection uses different inoculation routes including IV, intranasal (IN), subcutaneous (SC) and intratracheal (IT) administration, and also requires high viral doses of $10^{6}-10^{7} \mathrm{pfu}$ to induce clinical disease. Inoculation with doses $<10^{6}$ pfu results in a milder course of disease, which most animals survive ( [Zaucha et al., 2001], [Hooper et al., 2004], [Stittelaar et al., 2005], [Stittelaar et al., 2006] and [Saijo et al., 2006]). Additionally, working with MPXV and VARV is technically challenging, as it requires biosafety level 3 or 4 laboratories, respectively. Furthermore, macaques are relatively expensive animals compared with marmosets. Therefore, it would be useful to develop a new NHP model in which infections with OPVs other than VARV and MPXV induced a disease comparable to human smallpox.

In 2002 a lethal atypical epizootic OPV infection was reported in a colony of 80 New World monkeys in Lower Saxony, Germany (Mätz-Rensing et al., 2006). Sequencing and molecular characterization identified the virus as a new CPXV named calpox virus, after its host Callithrix jacchus, the common marmoset (Ellerbrok, unpublished data). Phylogenetic analyses revealed that this virus is related to, but distinct from known CPXV strains, which form a heterogeneous group of viruses within the genus Orthopoxvirus. The analysis of the natural outbreak in 2002 suggested that this virus infection in the common marmoset could serve as a valuable model system for smallpox virus infection of man. Therefore, the aim of the present study was to characterize the clinical course and pathology of calpox virus infection of common marmosets.

\section{Materials and Methods}

\section{Animals}

Twenty-eight healthy, sexually mature, common marmosets of different ages and sexes were obtained from the breeding colony of the German Primate Center (Table 1). During the experiments the animals were housed in single cages $(130 \times 53 \times 80 \mathrm{~cm})$ with olfactory and acoustic contact with each other. They were allowed free access to food and water and had routine environmental enrichment. Animal rooms were maintained at $25^{\circ} \mathrm{C}$ on a $12 \mathrm{~h} \mathrm{light}$ and dark cycle. Marmosets were fed primate pellets every day, supplemented by fruit and commercial paps. All animals were fed, tended and maintained according to the German Animal Protection Act. All animal experiments were approved by the responsible veterinary authorities (approval numbers 33.42502/08-07.05, 33.42502-04-019/07 and 33.42502/08-02.04) and performed in accordance with EU guidelines for the accommodation and care of animals used for experimental and other scientific purposes. Animals were checked clinically twice daily. Blood samples were collected twice weekly. Moribund or terminally ill animals were humanely 
sacrificed using an overdose of barbiturates. Complete necropsy examinations were performed on all animals, either after destruction or immediately after they were found dead. A complete range of organs was collected for microscopical, electron microscopical and virological investigations.

\section{Virus and Infection}

The calpox virus was propagated in Hep2 cells and stored in aliquots at $-70^{\circ} \mathrm{C}$. The median tissue culture infectious dose of the virus stock was determined by plaque assay before use in the infection experiments. The marmosets were infected by the IV, oropharyngeal (ORO) or IN route with different infectious doses of calpox virus (Table 1). For virus administration, marmosets were anaesthetized by intramuscular injection of $0.1 \mathrm{ml}$ per $200 \mathrm{~g}$ body weight of a mixture of $5 \%$ ketamine, $1 \%$ xylazine and $0.01 \%$ atropine. Calpox virus was administered IV into the saphenous vein in a volume of $500 \mu$ l. ORO virus administration was performed by dropping $100 \mu \mathrm{l}$ of the virus solution into the rear of the oral cavity. IN inoculation was carried out by pipetting $50 \mu \mathrm{l}$ virus solution into each nostril.

\section{Microscopy}

Tissue samples were fixed in $10 \%$ neutral buffered formalin and processed routinely. Sections were stained with haematoxylin and eosin (HE) using the Varistain Gemini automated stainer (Thermo Fisher Scientific, Frankfurt/Main, Germany). Sections of selected tissue samples were analyzed by immunohistochemistry (IHC) for detection of virus antigens using human anti-VACV immunoglobulin (Omrigam 5\%; 1 in 500 dilution) as the primary antibody and goat anti-human immunoglobulin (Ig) G antibody conjugated to biotin (Invitrogen, Darmstadt, Germany; 1 in 500 dilution) as secondary reagent. IHC was performed by use of a NexES-IHC staining module (Ventana, Illkirch, France). Selected sections of skin and liver samples were processed for transmission electron microscopy (TEM) after glutaraldehyde fixation (2.5\%) and embedding in epon.

\section{Results}

\section{Intravenous Infection}

In order to prove that the calpox virus isolate induced a disease comparable to that observed in the natural outbreak in a New World monkey colony, eight test animals were inoculated IV with $1.3 \times 10^{7} \mathrm{pfu}$ (animals $1-3$ ), $1.0 \times 10^{4} \mathrm{pfu}$ (animals 4-6) or $1.25 \times 10^{7} \mathrm{pfu}$ (animals 7 and 8). IV inoculation of the virus led to a rapidly developing fulminant disease at all three doses. All animals died between 4 and 7 days post infection (dpi).

The first clinical signs were respiratory difficulty, depression and anorexia, which preceded death by 1 day. Gross necropsy examination showed that all eight animals had lesions identical to those reported in the natural outbreak and comparable to those described in other OPV infections. Some animals developed moderate SC oedema of the pharyngeal region. They began to show evidence of a mild exanthema and enanthema at 5 dpi. Cutaneous erythema or single small macular lesions appeared on the face, trunk and mucous membranes. Single macules developed into small papular or vesicular lesions depending on the survival time of the host. The papular skin lesions appeared as pale tan to white foci that later became reddened and slightly raised, reaching a diameter of 2-3 mm (Fig. 1). They were often found in association with focal dermal haemorrhages. The average number of skin lesions found on one animal was approximately 10 , with distribution mostly over the facial region, ventral abdomen and inguinal areas. All marmosets developed splenic lymphoid hyperplasia and marked lymphadenomegaly of submandibular, axillary and inguinal lymph nodes accompanied by moderate haemorrhage of these nodes. Acute moderate transmural haemorrhage occurred in the large intestine of all animals, often in association with haemorrhagic mesenteric lymph nodes (Fig. 2). Acute moderate mucosal haemorrhage was observed within the urinary bladder (animals 3-8) and acute moderate to severe haemorrhage occurred in the liver (animals 1-5) and testes (animal 7). 
Microscopically, the most prominent finding was multifocal vesicular dermatitis, with cutaneous and SC haemorrhage affecting the skin and haemorrhages of the oral mucosa. The cutaneous lesions were characterized by focal epidermal necrosis, acanthosis and acantholysis leading to vesiculation typical of human pox-related exanthema (Fig. 3). Individual cell necrosis occurred within the stratum basale and the deep stratum spinosum. There was a sparse infiltration of the affected epidermis with neutrophils admixed with cellular debris. Multinucleated syncytial keratinocytes were observed occasionally in the epithelium of the skin and the mucous membranes adjacent to areas of necrosis and degeneration. Haemorrhage into the vesicles was occasionally observed. Follicular and sebaceous epithelia were also affected, developing single cell necrosis and inflammatory cell infiltration, whereas apocrine glands were spared.

Numerous characteristic intracytoplasmic inclusion bodies (Guarnieri bodies) were found in enlarged vacuolated or degenerate cells (Fig. 3). The Guarnieri bodies measured 2-8 $\mu \mathrm{m}$ and were distributed randomly within the altered epithelium. Virus antigen was detected most frequently within altered keratinocytes in dermal lesions.

The liver contained disseminated foci of acute haemorrhage and swollen hepatocytes with vacuolated cytoplasm, cytoplasmic inclusion bodies and single cell necrosis (Fig. 4). There was a moderate generalized circulating neutrophilia. Splenitis occurred as foci of necrosis centered on the germinal centres of the lymphoid follicles. These structures were infiltrated by macrophages and neutrophils admixed with cellular debris. Lymphoid hyperplasia was present in otherwise unaffected lymphoid follicles. The inguinal lymph nodes showed a severe necrotizing lymphadenitis accompanied by haemorrhage. Other lymph nodes had follicular hyperplasia with activation of the germinal centres.

Within the colon and small intestine of all animals there was severe acute focal transmural haemorrhage (Fig. 5) and focal erosive enteritis. Severe acute diffuse interstitial haemorrhage was found within the testes of one animal (Fig. 6) and there was multifocal haemorrhage within the mucosa of the urinary bladder of two animals.

Calpox virus genetic material was detected in all investigated tissues of the eight marmosets by quantitative real-time polymerase chain reaction (PCR). The detection of high copy numbers of viral DNA and mRNA in all tissues indicated a fulminant and generalized infection of marmosets infected by the IV route (Kramski et al., 2010).

\section{Oropharyngeal Infection}

Five marmosets were inoculated with $2.5 \times 10^{7}$ pfu of virus by the ORO route. Only one animal (number 9) showed clinical signs of infection and was humanely sacrificed at 13 dpi because of marked dyspnoea caused by severe laryngeal oedema and papulovesicular laryngitis. Calpox virus was detected in the blood of this animal by PCR. All other organs were unaffected. The other animals of this group remained healthy with no signs of infection. Calpox virus was not detected in the blood and virus-specific antibodies were not detected in the serum over a period up to $42 \mathrm{dpi}$ by use of an indirect immunofluorescence assay (Kurth et al., 2009).

\section{Intranasal Infection}

Six groups of two animals were each inoculated IN with different doses of virus (Table 1). Two marmosets were inoculated with $2.3 \times 10^{6}$ pfu (animals 10 and 11) and two marmosets were given $3.5 \times 10^{5}$ pfu (animals 12 and 13). In all four animals a lethal course of disease was induced. All four animals developed typical clinical signs of generalized OPV infection and died at 9-10 dpi. The next group of animals was given $3.5 \times 10^{4} \mathrm{pfu}$ (animals 14 and 15), $3.5 \times 10^{3} \mathrm{pfu}$ (animals 16 and 17), $5.0 \times 10^{2}$ pfu (animals 18 and 19) and $1.0 \times 10^{2}$ pfu calpox virus (animals 20 and 21) (Table 1). Animals 14-17 developed less pronounced alterations compared with the first four animals inoculated IN. All four animals were humanely sacrificed at $14 \mathrm{dpi}$. The expression of exanthema and enanthema was greater in the two animals given the higher dose (animals 14 and 15). From the lowest dose group (animals 18-21) only one animal (number 18) became infected. None of the three surviving marmosets showed any signs of infection or developed virus-specific antibodies (data not shown). Two of them were successfully reinoculated with a higher dose of virus (animals 19 and 20). Both of 
these animals developed typical clinical signs of poxvirus infection after reinoculation with $3.5 \times 10^{3}$ pfu and died 14 days after reinoculation. Animal 21 did not show any signs of infection.

The lethal dose of $8.3 \times 10^{3} \mathrm{pfu}$ deducted from the limited in-vivo titration described above was administered to seven animals (animals $22-28$ ) by the IN route. These animals served as controls in several subsequent vaccination studies. The first clinical signs were noticed at $10 \mathrm{dpi}$. Infected animals showed respiratory difficulty accompanied by nasal discharge. All seven animals died between 10 and $15 \mathrm{dpi}$.

Gross necropsy examinations revealed changes that were almost identical to those induced by IV infection. There was marked SC oedema and erythema of the face and the neck region, varying in degree depending on the infectious dose and time. Confluent or single smallpox-like vesicular lesions were scattered on the skin of the face (Fig. 7 and Fig. 8), abdomen and thighs. Typical haemorrhagic and umbilicated vesicular lesions distributed over the face, body and thighs were seen in animals given the lethal dose of $8.3 \times 10^{3} \mathrm{pfu}$ (Fig. 9). Additionally, there was severe ulceration of the mucous membranes, particularly affecting the gingiva, tongue and larynx. Whereas few lesions were observed on the skin of animals infected via the IV route, 20-30 single vesicules or papules were counted on each animal infected by the IN route. Furthermore, moderate splenomegaly, alveolar oedema in the lung, oedema of the tonsils, lymphoid hyperplasia with focal haemorrhage and acute necrosis of the submandibular and retropharyngeal lymph nodes was observed. Haemorrhagic cystitis was a frequent finding in animals given the lethal dose of $8.3 \times 10^{3} \mathrm{pfu}$, indicating a severe systemic infection. No specific lesions were detected in the heart, skeletal muscle, lung, kidney, nervous system, eye or brain.

Microscopical investigation of the tissues revealed typical vesicular skin lesions characterized by focal necrosis, acantholysis, acanthosis, syncytia formation of the basal keratinocytes and accumulation of Guarnieri bodies in altered epithelial cells accompanied by haemorrhage (Fig. 10 and Fig. 11). Minimal haemorrhage and severe congestion were found in the lung and liver. Hepatocellular swelling and vacuolation was a consistent finding. Hepatocyte nuclei varied in size and these cells sometimes had multiple nuclei or mitoses or single cell necrosis. Endothelial cells lining sinusoids were swollen and necrotic. Hyperplastic follicles were noted within the enlarged spleen and lymph nodes. The submandibular and retropharyngeal lymph nodes had severe necrotizing inflammation accompanied by haemorrhage and accumulation of apoptotic cells in the remains of follicles. All other tissues lacked specific pathological changes.

\section{Immunohistochemical and Ultrastructural Findings}

IHC and electron microscopy confirmed the presence of calpox virus-infected cells in different tissues. OPV antigens were visualized in the skin, liver and lymph nodes. In cutaneous lesions the virus was present in degenerate epithelial cells, dermal macrophages and altered sebaceous glands (Fig. 12 and Fig. 13). In lymphoid tissue, virus antigen was found in monocytes, macrophages and endothelial cells. Virus antigen was also detected in the liver beneath foci of affected hepatocytes. Electron microscopy revealed virus particles with OPV-like morphology in intracytoplasmic inclusions in epithelial cells and liver cells.

Ultrastructurally, intracytoplasmic inclusions were comprised of mature virus particles measuring $140 \times 260 \mathrm{~nm}$ (Fig. 14). The enveloped virus particles were ovoid to brick-shaped with a pale central zone, having features characteristic of OPV (Fig. 15).

The virus load in tissue samples of all animals inoculated IN reached virus titres vastly in excess of the viral inocula (Kramski et al., 2010). The virus distribution and final viral loads were comparable to the IV infection experiments. In brief, the highest loads of virus DNA were found in the skin, lung, spleen, lymph nodes, oesophagus and tonsils ( $>10^{5}$ calpox genome equivalents $/ 10^{4}$ copies of the $c$-myc gene) in all animals infected via the IN route. 


\section{Discussion}

This report describes the microscopical and ultrastructural changes in marmosets infected experimentally with calpox virus. Calpox virus is a new CPXV isolated from a lethal OPV outbreak in New World monkeys (Mätz-Rensing et al., 2006). In natural VARV and MPXV infections, unvaccinated human patients generally develop symptoms and some infected individuals die. However, all the marmosets exposed to calpox virus and demonstrating productive infection developed clinical signs and died from infection, independent of the route of inoculation. Serological and microbiological investigations have shown that these animals do not have underlying immunodeficiency, which might explain their high susceptibility and the lethal outcome of the infection. Calpox virus-exposed animals that remained healthy were negative for virus genomic DNA and virus-specific antibodies, suggesting an unsuccessful infection.

As natural VARV transmission is primarily by aerosol, we sought to investigate natural routes of infection (Esposito and Fenner, 2001). The main route of virus transmission via the respiratory tract was mimicked by IN application of the virus. Viral doses as low as $5 \times 10^{2}$ pfu led to lethal infection in approximately one-third of the inoculated animals (data not shown). An infectious dose of around $8 \times 10^{3} \mathrm{pfu}$, derived from limited in-vivo titration, reproducibly led to disease with similar signs to those observed in the natural outbreak (Mätz-Rensing et al., 2006).

The clinical and pathological features of the disease in marmosets were comparable in many aspects to human VARV infection ( [Fenner et al., 1988] and [Esposito and Fenner, 2001]). Different clinical manifestations of VARV infection are reported. The most common clinical form produced by both VARV major and minor is the ordinary type. According to the severity of the rash on the face and upper limbs, ordinary smallpox is subdivided into the confluent subtype (confluent rash on face and forearms), the semi-confluent subtype (confluent rash on face and discrete rash elsewhere) and the discrete subtype (areas of normal skin between the pustules). The modified type is usually non-fatal and the rash evolves quickly with more variation in lesion size than in discrete ordinary smallpox. In the flat type, confluent or semi-confluent pustules remain flat, soft and non-suppurative. Widespread haemorrhages in skin and mucous membranes are characteristic for the haemorrhagic type. The flat type and the haemorrhagic type of VARV major are usually fatal. Independent of the route of infection, all experimentally infected marmosets died within 1-2 days after onset of clinical signs. In contrast to the VARV infection, no recovery from the disease after onset of clinical signs was observed.

Independent of the dose of infection, all infected animals developed typical clinical signs of OPV infection. Characteristic pathological features in the monkeys were severe oedema of the neck region, focal epithelial and mucosal lesions characterized by severe epidermal haemorrhage and vesiculation induced by epidermal acantholysis. Ulcerative mucosal lesions were found on the gingiva, the tongue or in the pharyngeal region and less consistently on the mucous membranes of the oesophagus and urinary bladder. As in human smallpox infection, the rash appeared first in the mouth, on the pharynx, face and forearms and then spread to the trunk and legs. Lesions rarely appeared on the palms and soles, which is in contrast to smallpox. The rash became vesicular and then pustular within 1-2 days.

Typical pustules with crust formation were not observed in monkeys. Unlike MPXV and VARV patients who develop a more or less confluent rash ( [Jezek et al., 1987], [Fenner et al., 1988] and [Parker et al., 2007]), the number of papules was sparse. After IV inoculation, less than 10 typical papules were found. In contrast, after IN inoculation the number of cutaneous papules and vesicles increased up to 20 small lesions. After IV infection, cutaneous alterations were less pronounced compared with those of animals infected IN, probably due to the shorter incubation period. After IV infection the disease took a more haemorrhagic course with bleeding into the skin or the gastrointestinal tract, comparable to the haemorrhagic type of smallpox infection in man. Predilection sites of the cutaneous lesions were the face, abdomen and thighs.

Even a high calpox virus dose was not able to induce an infection featuring skin lesions that were distributed confluently over the body of the animals, a characteristic previously demonstrated in macaques infected with MPXV and VARV, when more than 500 cutaneous lesions were counted ( [Hooper et al., 2004], [Jahrling et al., 2004] and [Stittelaar et al., 2005]). The clinical picture of calpox virus infection further differed in the morphology of the skin lesions, which remained flat and small in size (2-5 mm in diameter), whereas VARV induced more confluent lesions, which reached a diameter of $>10 \mathrm{~mm}$. The lesions were comparable with the flat type of VARV infection. 
The presence of numerous huge eosinophilic granular intracytoplasmic inclusion bodies in the cutaneous and mucosal lesions within degenerate keratinocytes is a consistent histological finding in both diseases. Immunohistochemical investigations revealed that OPV antigens were only detectable in tissues showing morphological alterations and were most prominent within epithelial cells, macrophages and endothelial cells. This finding demonstrates that the antigen concentration must be above a certain threshold, as quantitative PCR showed that virus genomes could be detected in all tissues investigated (Kramski et al., 2010). The presence of OPV antigen correlated with the detection of virus particles by electron microscopy. Virus particles showed OPV-like morphology within intracytoplasmic inclusions.

Further typical findings in the marmosets infected with calpox virus were necrotic foci in the spleen and liver. The mucosa of the urinary bladder also seems to be a predilection site for infection. In contrast, alterations of the urinary bladder or hepatic involvement are uncommon features of the experimental MPXV infection in other animal models (Zaucha et al., 2001). In this aspect the new marmoset model could offer more insight into the complex pathogenesis of systemic orthopox infection.

Pathogenetically, it was assumed that the nasal epithelium and the nasal-associated lymphoid tissue (NALT) served as a principal target for primary infection following IN infection. The severity of the lesions within the laryngopharyngeal area and tonsils in the early course of the disease suggested that these organs were additional, although subordinate, sites of primary replication. The distribution of lesions was consistent with lymphatic spread to the submandibular and axillary lymph nodes and systemic dissemination of the virus through a monocyte-associated viraemia, resulting in lesions affecting other lymph nodes, the spleen, liver, skin, oral mucosa, gastrointestinal tract, the reproductive system and bladder. The mononuclear phagocyte/dendritic cell system, as demonstrated by IHC, was the principal target within lymphoid tissues and may also have provided the means of entry into other systemic sites.

In contrast, experimental IV inoculation of the virus seemingly bypassed the early stages in the pathogenesis, namely the initial transmission and infection of primary target tissue, the incubation period and the associated prodrome. The IV infection presumably resembled the viraemia, leading to a rapid systemic course of the infection with haemorrhagic lesions in several organs.

Death may have resulted from a massive secretion of cytokines associated with circulating immune complexes and soluble calpox virus antigens as well as overwhelming virus replication in the organs in the second phase of viraemia, all leading to multiple organ failure. To improve the understanding of calpox virus pathogenesis, further research is needed. Newly established marmoset-specific cytokine real-time PCR assays may become a useful tool for the determination of the marmoset cytokine expression pattern during infection and vaccination studies.

In most NHP models using VARV or MPXV, IV inoculation, a non-physiological route of infection bypassing the mucosa, is used ( [Jahrling et al., 2004], [Rubins et al., 2004] and [Edghill-Smith et al., 2005]). In these NHP models the IV inoculation route circumvents a primary replication of the virus in regional lymph nodes and the successive systemic spread via the lymphatic system (first viraemia). Instead, the virus is immediately spread via the bloodstream, inducing a disease with numerous lesions characteristic of a post-secondary viraemia. In addition to employing a non-physiological route of infection, another major drawback in established NHP models is that the virus has to be administered in very high doses to induce a severe or fatal disease. At least $10^{6}$ pfu of MPXV must be injected SC to induce a lethal infection in cynomolgus macaques (Saijo et al., 2006), and IV inoculation of at least $5 \times 10^{7} \mathrm{pfu}$ of MPXV led to a fatal infection in cynomolgus and rhesus macaques ( [Earl et al., 2004] and [Hooper et al., 2004]). The three inoculation routes established for the MPXV macaque model that come closest to the natural route of smallpox infection were IT ( [Stittelaar et al., 2005] and [Stittelaar et al., 2006]), aerosolized (Zaucha et al., 2001) and IN administration of MPXV (Marriott, 2008). Even so, very high doses of $10^{7}$ pfu are needed to induce a severe or lethal infection. This is similar to the VARV macaque model where extremely high virus doses of at least $10^{8}$ pfu given IV are needed to induce a systemic infection ( [Jahrling et al., 2004] and [Rubins et al., 2004]).

In the present NHP model, IN application mimicking natural OPV infection proved to be a successful strategy for administering calpox virus to marmosets. An association was observed between the infectious dose and the course of infection. High virus doses of $2.3 \times 10^{6}$ and $3.5 \times 10^{5}$ pfu rapidly led to death within 9-10 days, associated with high viral loads in blood (data not shown). Using 
decreasing infectious doses of calpox virus, a median $50 \%$ monkey infectious dose $\left(\mathrm{MID}_{50}\right)$ of $8.3 \times 10^{2}$ pfu was estimated, showing that calpox virus is highly pathogenic for marmosets. This $M I_{50}$ is approximately 10,000 times lower than that needed in any other NPH model for OPV infection and might be closer to naturally acquired VARV and MPXV infections. Therefore, the low MID ${ }_{50}$ needed for induction of disease and pathology similar to that induced by MPXV or VARV infection implies that the calpox virus/marmoset model is reliable and might have several advantages compared with other NHP model systems.

Epidemiological investigations of the natural calpox virus outbreak in the colony of New World monkeys gave no evidence for a transmission to man, even when there was close contact with diseased animals. Sequence similarities of the calpox virus to published CPXV sequences allow calpox virus to be defined tentatively as the species CPXV in the genus OPV. CPXV is classified as a biosafety level 2 pathogen so experiments with this virus may be performed by a larger number of laboratories. Whereas some human patients or experimental animals infected with VARV or MPXV developed symptoms and then recovered, all diseased marmosets died or had to be humanely sacrificed. Animals surviving virus inoculation showed neither clinical nor immunological nor molecular markers of an infection. The readout of the success or failure of vaccines or therapeutic treatments is therefore straightforward in comparison to other NHP models, and there is no need to develop a scoring system for clinical signs.

Further advantages of using marmosets as experimental animals include their small size, reasonably sized housing space and easy handling. These animals can be socially housed, they reproduce well in captivity, are inexpensive to keep, have an economical purchase price and wild populations are not endangered. As the calpox virus/marmoset model overcomes major limitations of current primate models, it is suitable for studying virus pathology and for evaluating new vaccines and antiviral therapies. Since New World monkeys seem to be highly susceptible to the infection, the model could also help to deal with the disease in captive populations.

\section{Acknowledgments}

We are grateful to W. Henkel, K. Kaiser-Jarry, N. Knöchelmann, E. Lischka, J.-W. Sim-Brandenburg and $\mathrm{H}$. Zuri for excellent technical assistance and U. Erikli for copyediting. 


\section{References}

Baxby D, Ashton DG, Jones D, Thomsett LR, DenhamEM (1979) Cowpox virus infection in unusual hosts. Veterinary Record, 104, 175.

Baxby D, Bennett M, Getty B (1994) Human cowpox 1969 - 93: a review based on 54 cases. British Journal of

Dermatology, 131, 598 - 607.

Begon M, Hazel SM, Baxby D, Bown K, Cavanagh R et al. (1999) Transmission dynamics of a zoonotic pathogen within and between wildlife host species. Proceedings of Biological Science, 266, $1939-1945$.

Campe H, Zimmermann P, Glos K, Bayer M, Bergemann H et al. (2009) Cowpox virus transmission from pet rats to humans, Germany. Emerging Infectious Diseases, 15, 777 -780.

Centers for Disease Control and Prevention (2003) Multistate outbreak of monkeypox - Illinois, Indiana, and Wisconsin. Morbidity and Mortality Weekly Report, 52, 537 -540.

Chantrey J, Meyer H, Baxby D, Begon M, Bown KJ et al. (1999) Cowpox: reservoir hosts and geographic range. Epidemiology and Infection, 122, 455 - 460.

Czerny CP, Eis-Hubinger AM, Mayr A, Schneweis KE, Pfeiff B (1991) Animal poxviruses transmitted from cat to man: current event with lethal end. Zentralbl Veterinarmed B, 38, $421-431$.

DiGiulio DB, Eckburg PB (2004) Monkeypox in the Western hemisphere. New England Journal of Medicine, 350, $1790-1791$.

Earl PL, Americo JL, Wyatt LS, Eller LA, Whitbeck JC et al. (2004) Immunogenicity of a highly attenuated MVA smallpox vaccine and protection against monkeypox. Nature, 428, $182-185$.

Edghill-Smith Y, Golding H, Manischewitz J, King LR, Scott D et al. (2005) Smallpox vaccine induced antibodies are necessary and sufficient for protection against monkeypox virus. Nature Medicine, 11, $740-747$.

Eis-Hübinger AM, Gerritzen A, Schneweis KE, Pfeiff B, Puzllmann H et al. (1990) Fatal cowpox-like virus infection transmitted by cat. Lancet, 336, 880.

Esposito JJ, Fenner F (2001) Poxviruses. In: Fields' Virology, 4th Edit., Vol. 2, DM Knipe, PM Howley, DE Griffin, RA Lamb, MA Martin et al., Eds., Lippincott, Williams

Fenner F, Henderson DA, Arita I, Jezek Z, Ladnyi ID (1988) Pathogenesis, Pathology and Immunology of Smallpox; Smallpox and its Eradication. World Health Organization, Geneva, pp. 121 - 168. Hazel SM, Bennett M, Chantrey J, Brown J, Cavanagh R et al. (2000) A longitudinal study of an endemic disease in its wildlife reservoir: cowpox and wild rodents. Epidemiology and Infection, 124, 551- 562.

Hooper JW, Thompson E, Wilhelmsen C, Zimmerman M, Ichou MA et al. (2004) Smallpox DNA vaccine protects non-human primates against lethal monkeypox. Journal of Virology, 78, 4433 - 4443. Jahrling PB, Hensley LE, Martinez MJ, Leduc JW, Rubins KH et al. (2004) Exploring the potential of variola virus infection of cynomolgus macaques as a model for human smallpox. Proceedings of the National Academy of Sciences USA, 101, $15196-15200$.

Jezek Z, Szczeniowski M, Paluku K, Mutombo M (1987) Human monkeypox: clinical features of 282 patients. Journal of Infectious Diseases, 156, 293 - 298.

Kramski M, Mätz-Rensing K, Stahl-Hennig C, Kaup F-J, Nitsche A et al. (2010) A novel highly reproducible and lethal nonhuman primate model for orthopox virus infection. PLoS One, 5, e10412. Kurth A, Straube M, Kuczka A, Dunsche AJ, Meyer H et al. (2009) Cowpox virus outbreak in banded mongooses (Mungos mungo) and jaguarundis (Herpailurus yagouaroundi) with a time-delayed infection to humans. PLoS One, 4, e6883.

LeDuc JW, Jahrling PB (2001) Strengthening national preparedness for smallpox: an update. Emerging Infectious Diseases, 7, $155 \mathrm{e} 157$.

Mätz-Rensing K, Ellerbrok H, Ehlers B, Pauli G, Floto A et al. (2006) Fatal poxvirus outbreak in a colony of New World monkeys. Veterinary Pathology, 43, 212 - 218.

Marriott KA (2008) Characterization and description of a respiratory challenge model of poxvirus infection. Proceedings of the 17th International Poxvirus and Iridovirus Conference, Grainau, Germany, June 7 - 12.

Nalca A, Rimoin AW, Bavari S, Whitehouse CA (2005) Reemergence of monkeypox: prevalence, diagnostics, and countermeasures. Clinical Infectious Diseases, 41, $1765-1771$.

Parker S, Nuara A, Buller RM, Schultz DA (2007) Human monkey pox: an emerging zoonotic disease. Future Microbiology, 2, 17 - 34.

Pilaski J, Rosen A, Darai G (1986) Comparative analysis of the genomes of orthopoxviruses isolated from elephant, rhinoceros, and okapi by restriction enzymes. Archives of Virology, 88, 135 - 142. Rubins KH, Hensley LE, Jahrling PB, Whitney AR, Geisbert TW et al. (2004) The host response to smallpox: 
analysis of the gene expression program in peripheral blood cells in a non-human primate model. Proceedings of the National Academy of Sciences USA, 101, 15190 - 15195.

Saijo M, Ami Y, Suzaki Y, Nagata N, Iwata N et al. (2006) LC16m8, a highly attenuated vaccinia virus vaccine lacking expression of the membrane protein B5R, protects monkeys from monkeypox. Journal of Virology, 80, 5179 - 5188.

Stittelaar KJ, Neyts J, Naesens L, van Amerongen G, van Lavieren RF et al. (2006) Antiviral treatment is more effective than smallpox vaccination upon lethal monkeypox virus infection. Nature, 439, 745 748.

Stittelaar KJ, van Amerongen G, Kondova I, Kuiken T, van Lavieren RF et al. (2005) Modified vaccinia virus Ankara protects macaques against respiratory challenge with monkeypox virus. Journal of Virology, 79, 7845 - 7851.

Vorou RM, Papavassiliou VG, Pierroutsakos IN (2008) Cowpox virus infection: an emerging health threat. Current Opinion in Infectious Disease, 21, 153 - 156.

Zaucha GM, Jahrling PB, Geisbert TW, Swearengen JR, Hensley L (2001) The pathology of experimental aerosolized monkeypox virus infection in cynomolgus monkeys (Macaca fascicularis). Laboratory Investigation, $81,1581-1600$. 


\section{Tables and Figures}

Table 1. Inoculation route, inoculation dose and gross pathological findings in animals inoculated experimentally with calpox virus.

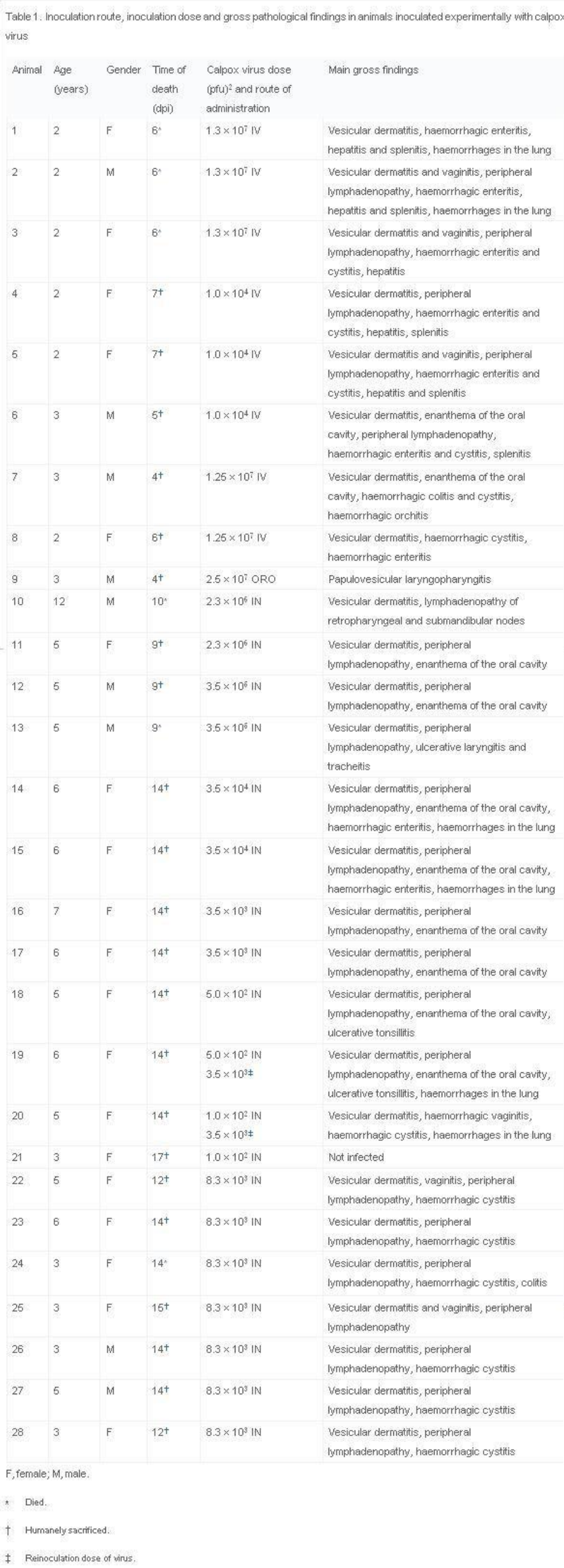


Figure 1. Animal number 6 showing moderate multifocal papular dermatitis of the upper lip (arrows) after IV calpox infection.

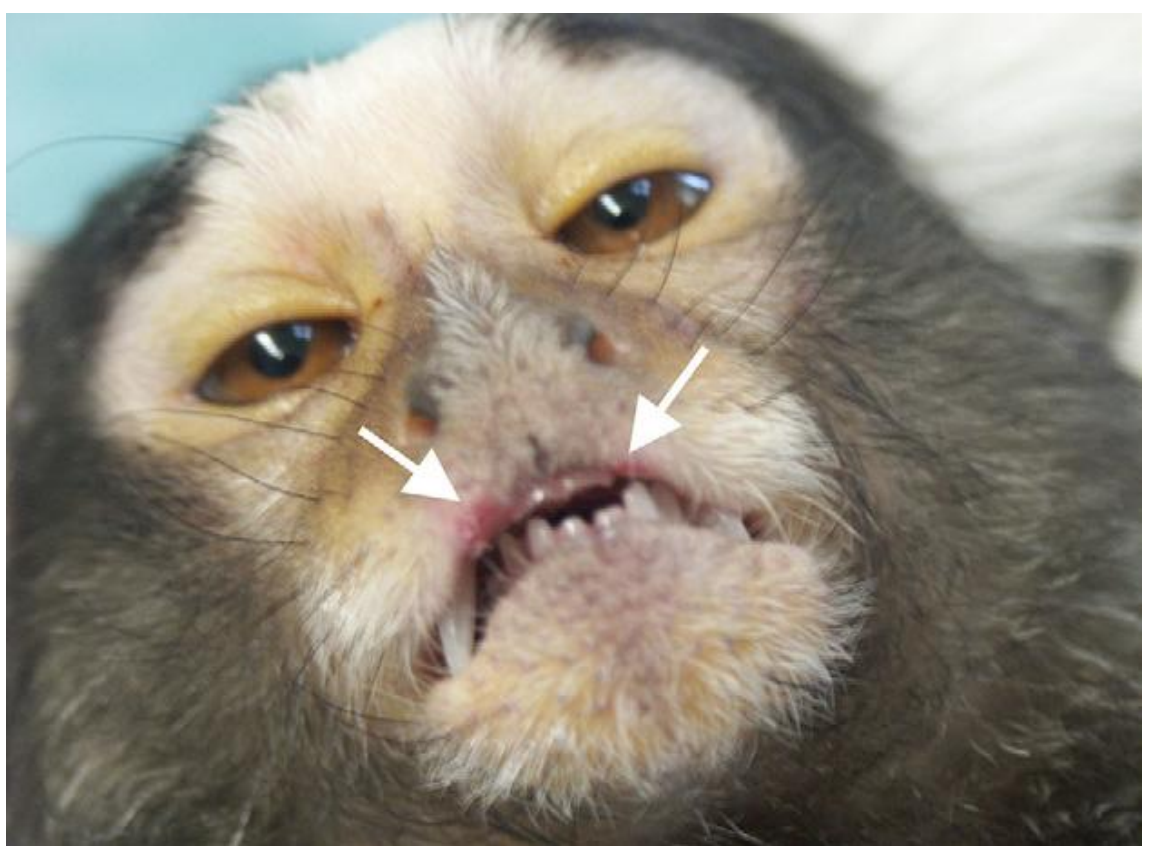

Figure 2. Severe petechiae of the large intestine after IV calpox infection of animal number 6.

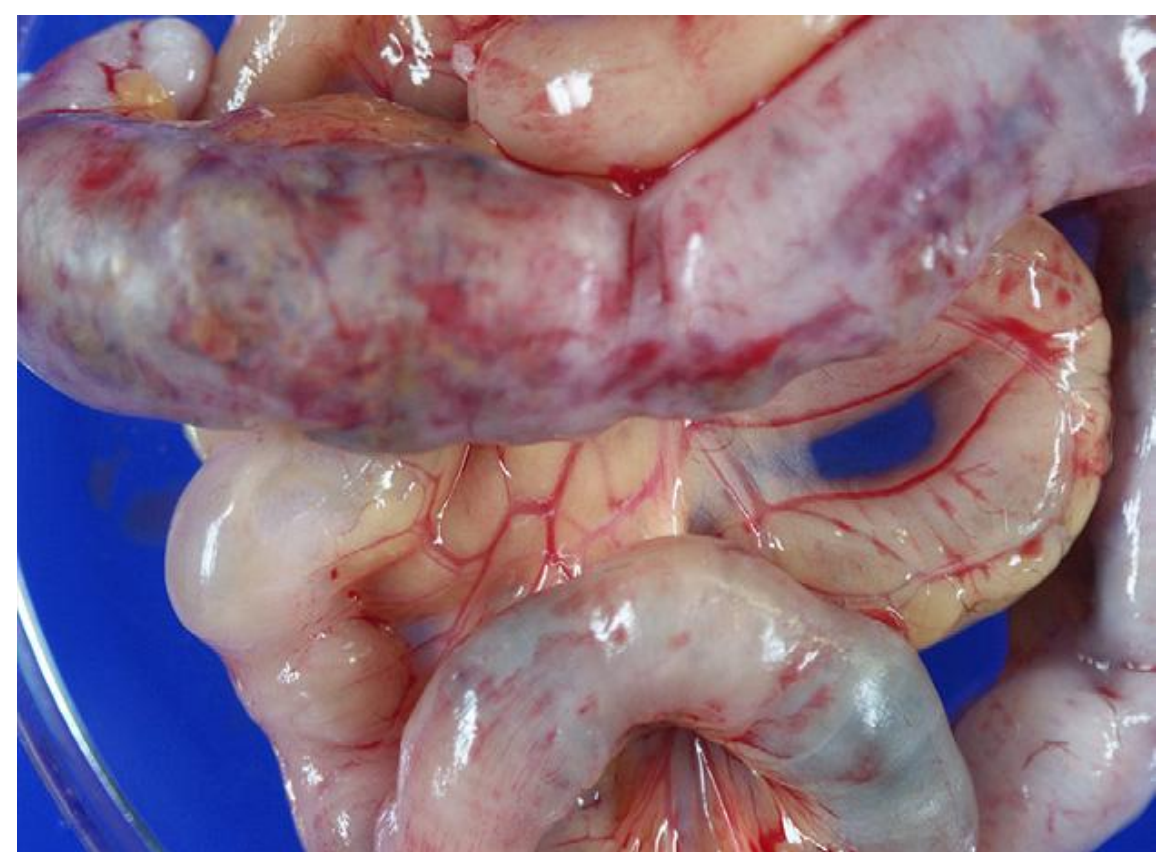


Figure 3. Acute focal vesicular dermatitis with acanthosis, acantholysis and early vesiculation with characteristic intralesional Guarnieri bodies (arrow) after IV calpox infection of animal number 4. HE. Bar, $50 \mu \mathrm{m}$.

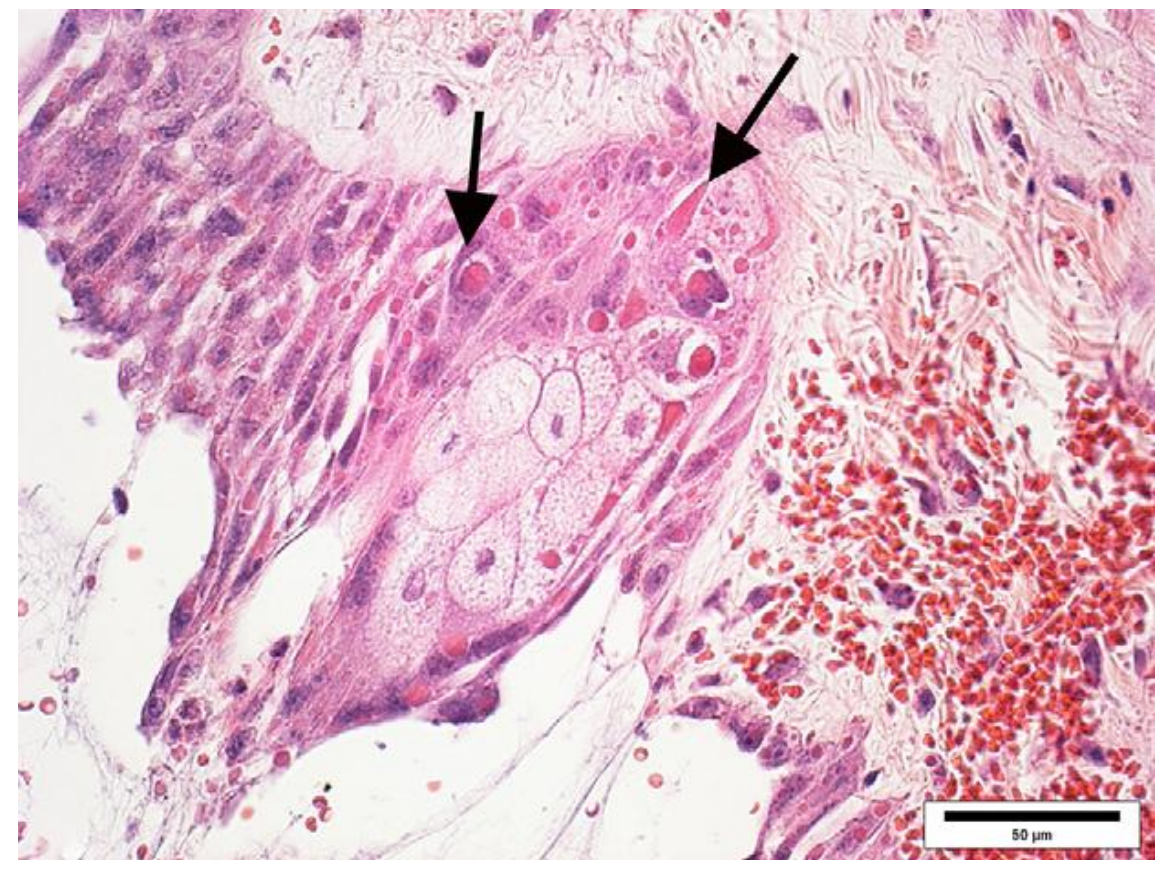

Figure 4. Acute focal necrotizing hepatitis with haemorrhage after IV calpox infection of animal number 5. HE stain. Bar, $50 \mu \mathrm{m}$.

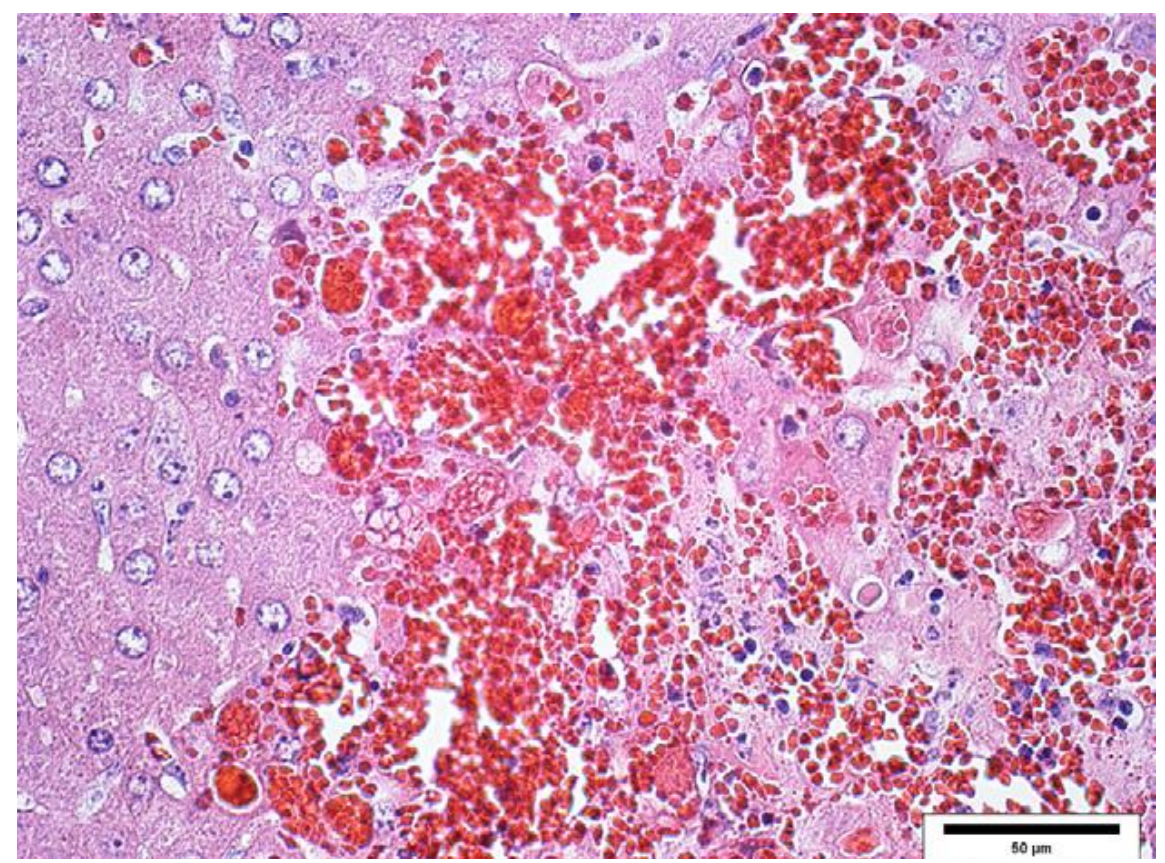


Figure 5. Acute multifocal haemorrhage within the mucosa of the large intestine after IV calpox infection of animal number 7. HE. Bar, $100 \mu \mathrm{m}$.

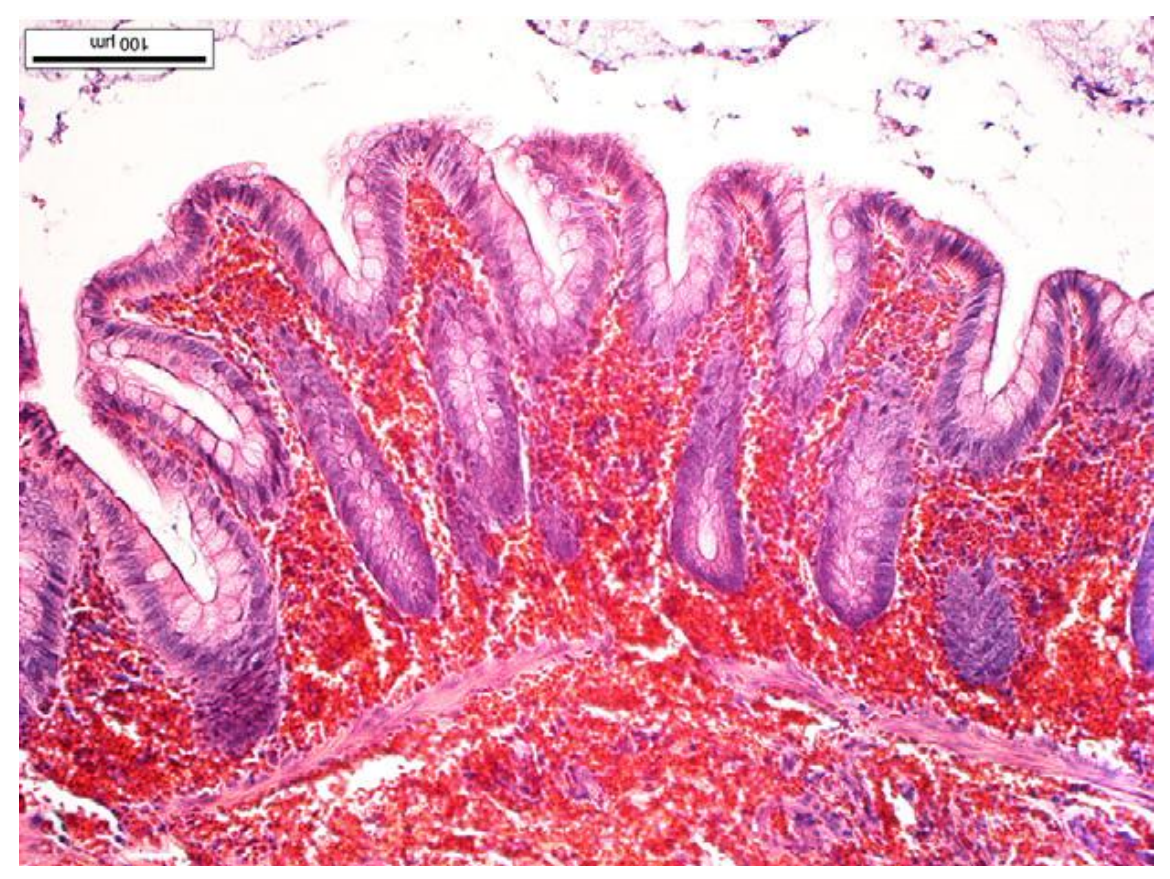

Figure 6. Acute multifocal haemorrhage within the testis after IV calpox infection of animal number 7. HE. Bar, $200 \mu \mathrm{m}$.

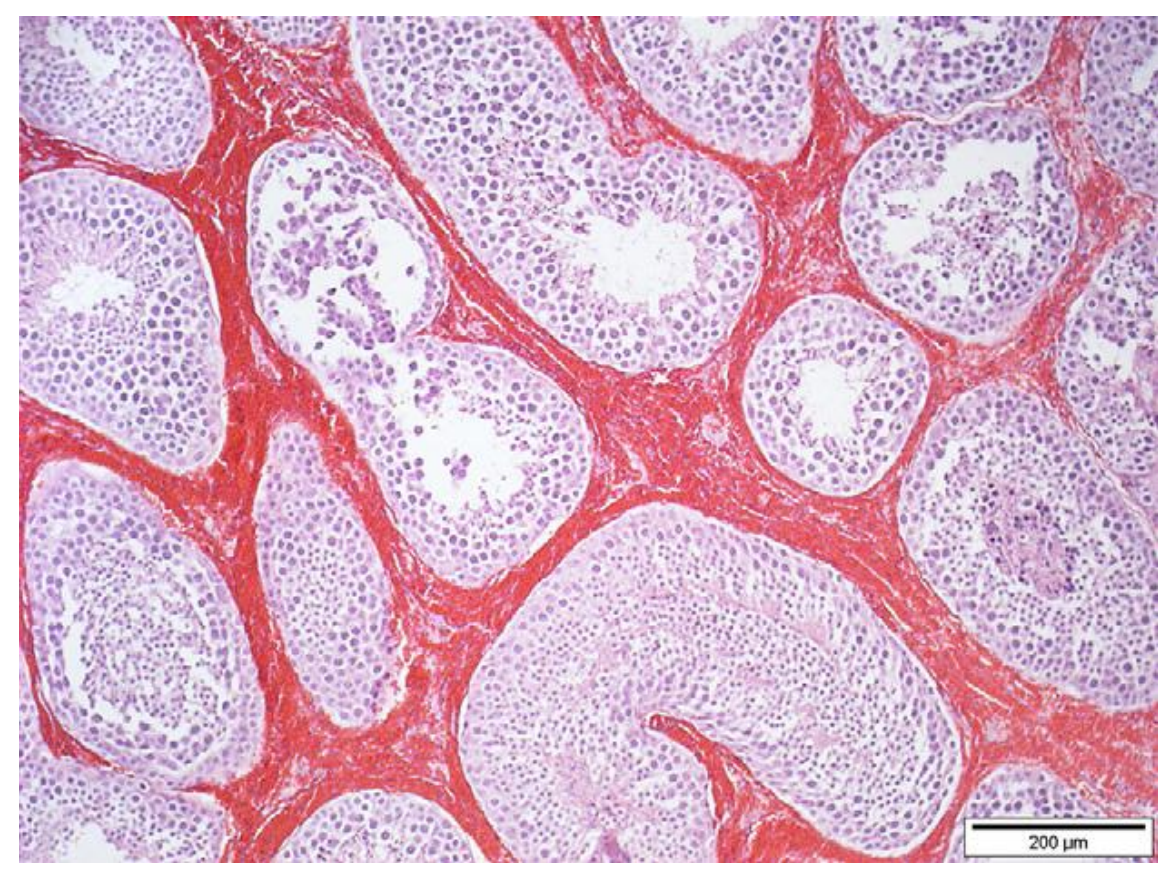


Figure 7. Severe erythema and vesicular alterations around both nostrils (arrow), the eyelid and within the corner of the mouth after IN calpox infection of animal number 15.

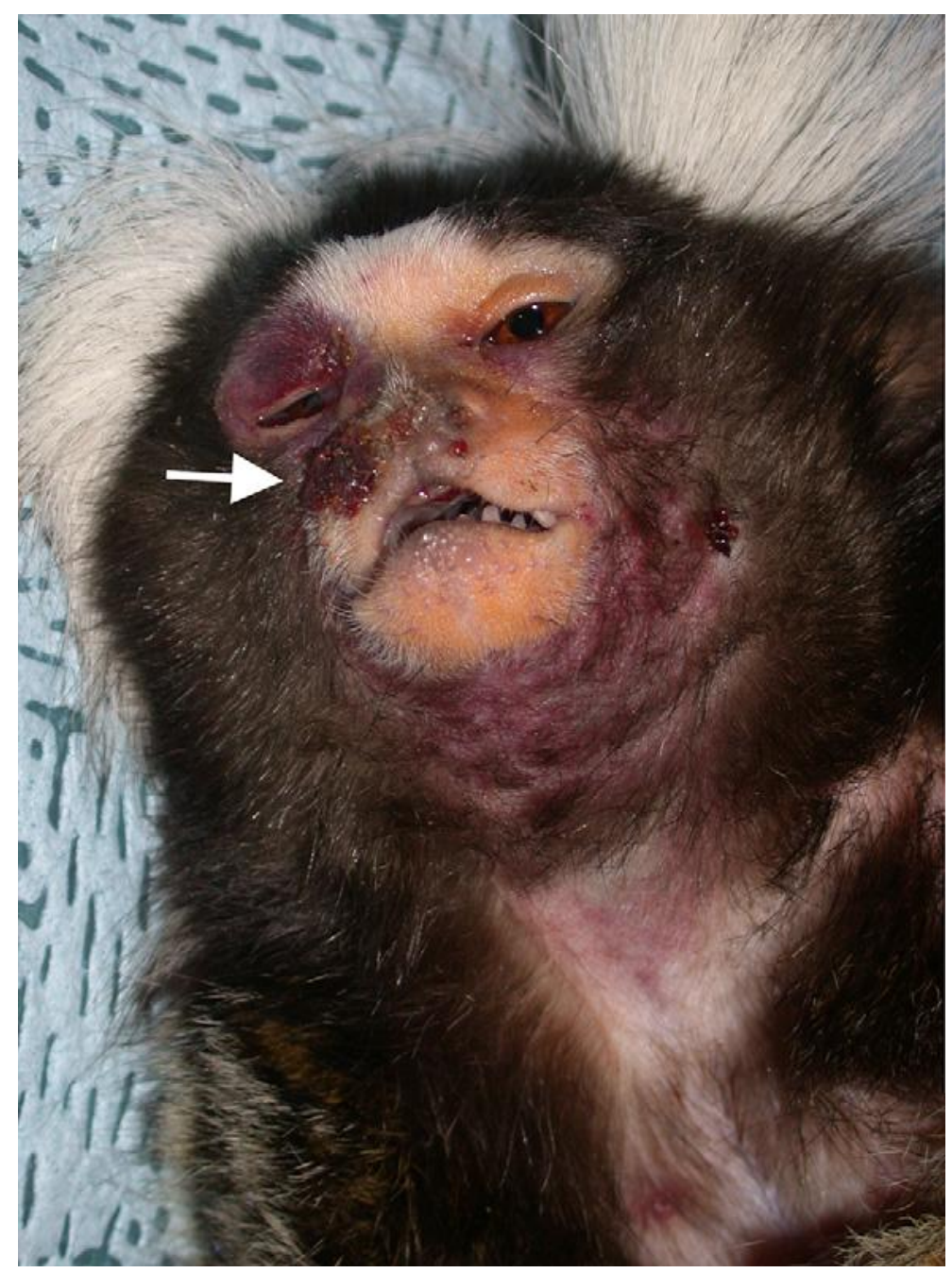


Figure 8. Moderate erythema and single vesicular alterations around both nostrils (arrows) accompanied by severe oedema of the neck after IN calpox infection of animal number 11 .

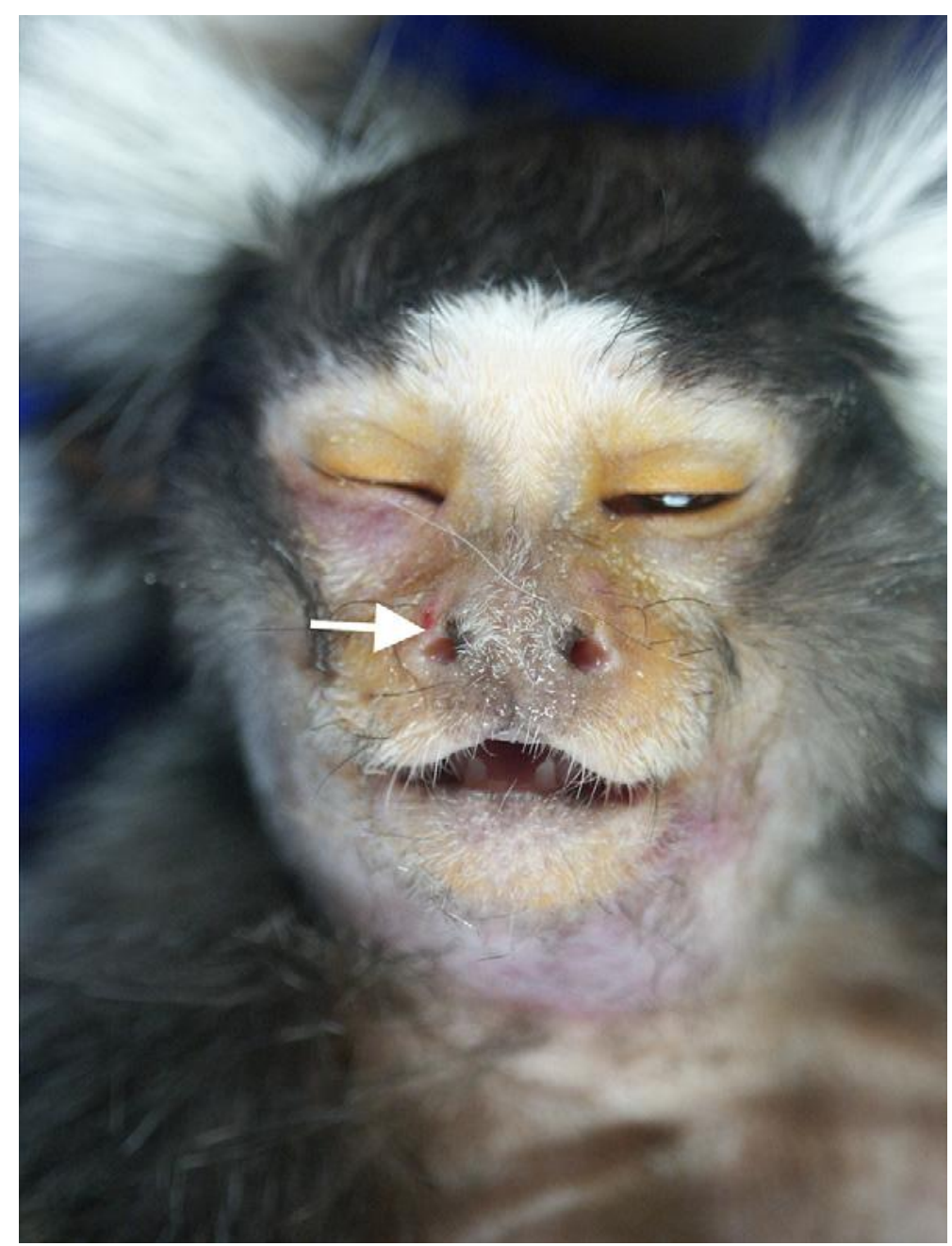


Figure 9. Single umbilicated vesicular lesions in the inguinal and axillary regions (arrows) after IN calpox infection of animal number 24.

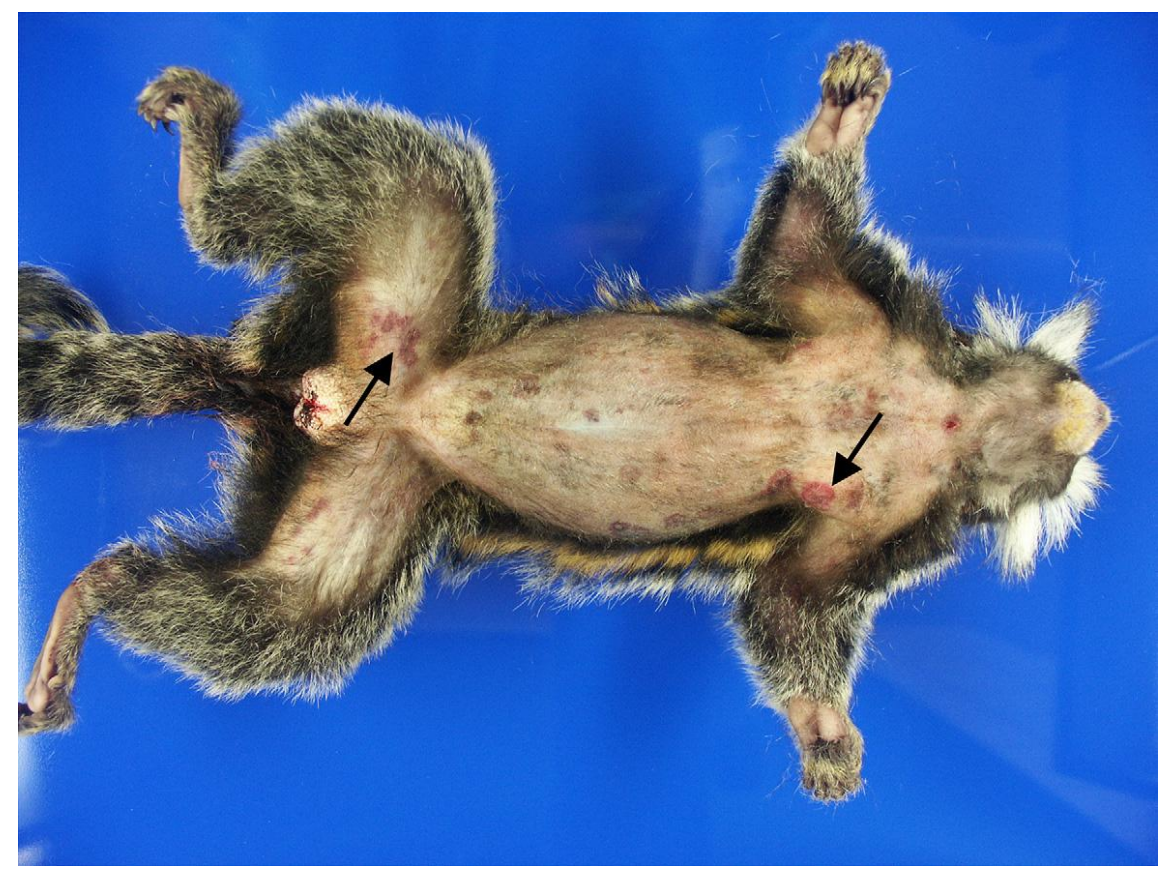

Figure 10. Severe focal vesicular dermatitis with marked intraepidermal haemorrhage after IN calpox infection of animal number 14. HE. Bar, $200 \mu \mathrm{m}$.

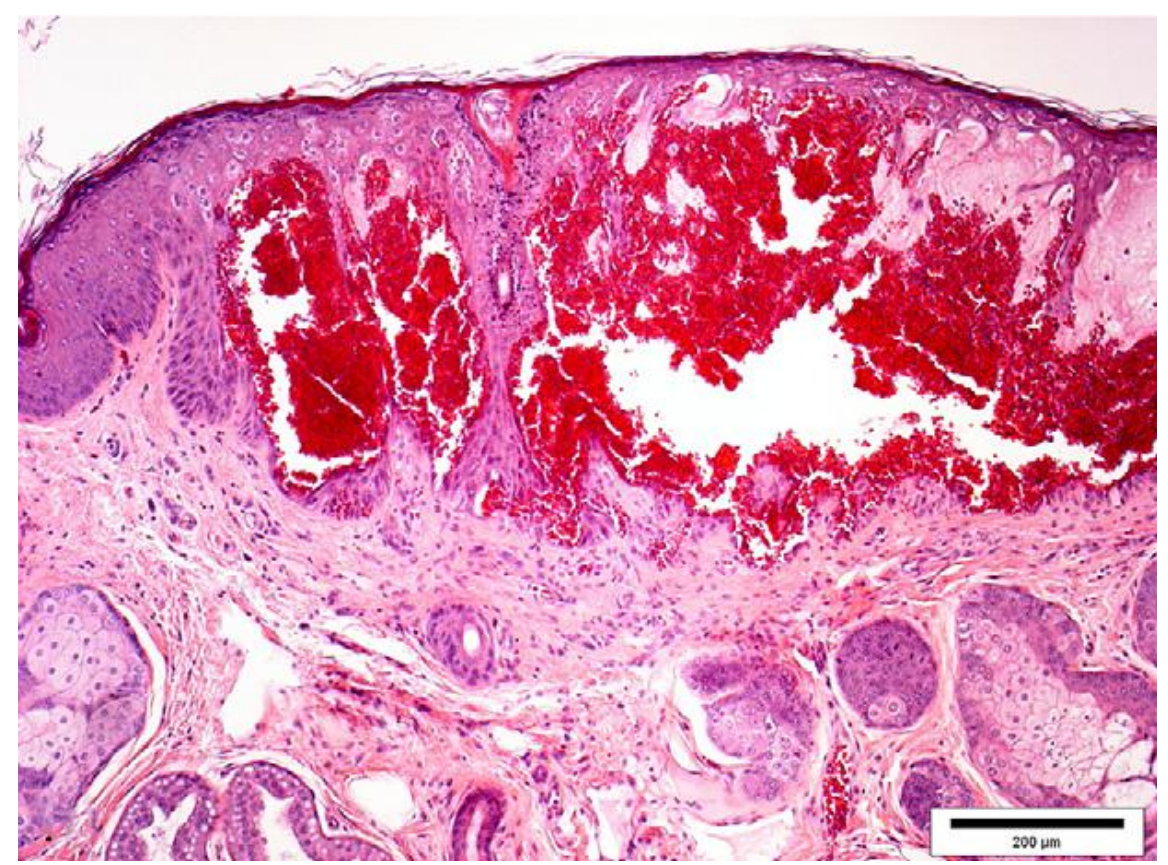


Figure 11. Severe focal vesicular dermatitis with marked intraepidermal haemorrhage and numerous intracytoplasmic inclusion bodies after IN calpox infection of animal number 16. HE. Bar, $200 \mu \mathrm{m}$.

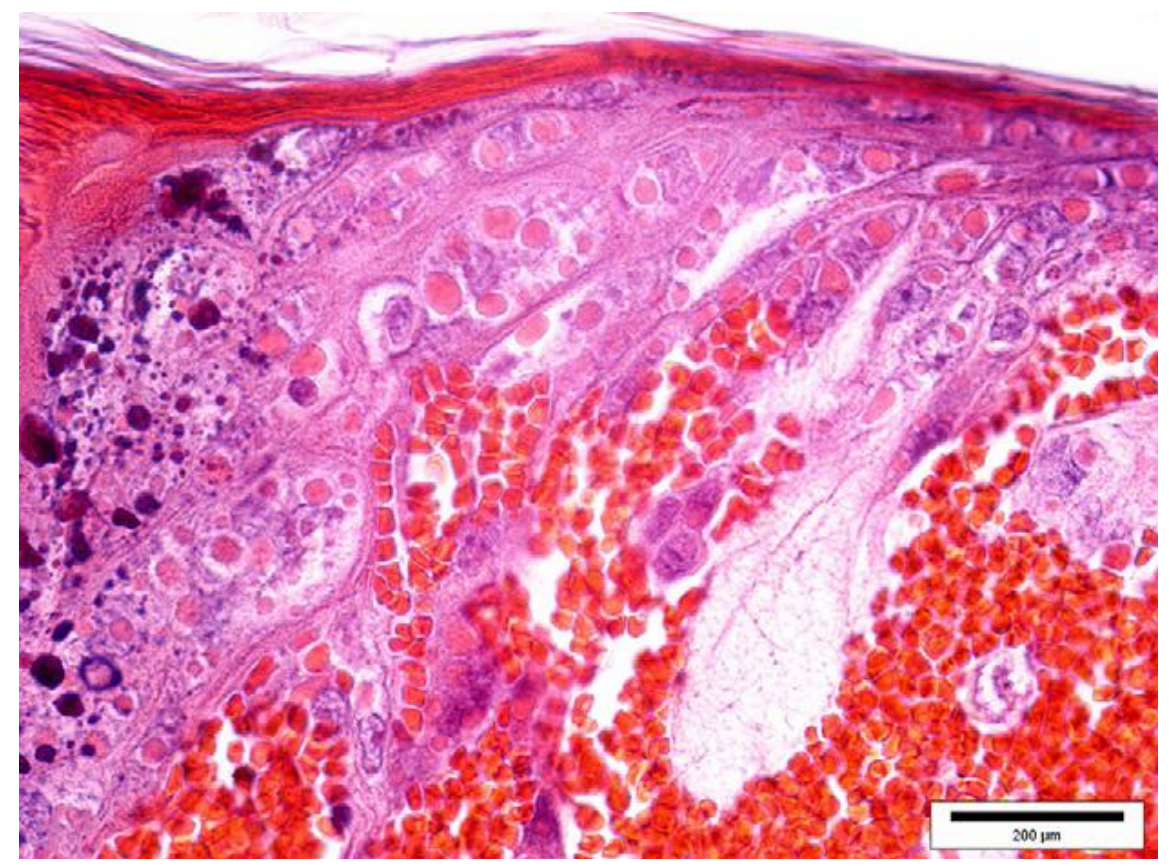

Figure 12. Virus antigen within infected epithelial cells (arrows) after IN calpox infection of animal number 11. IHC. Bar, $50 \mu \mathrm{m}$.

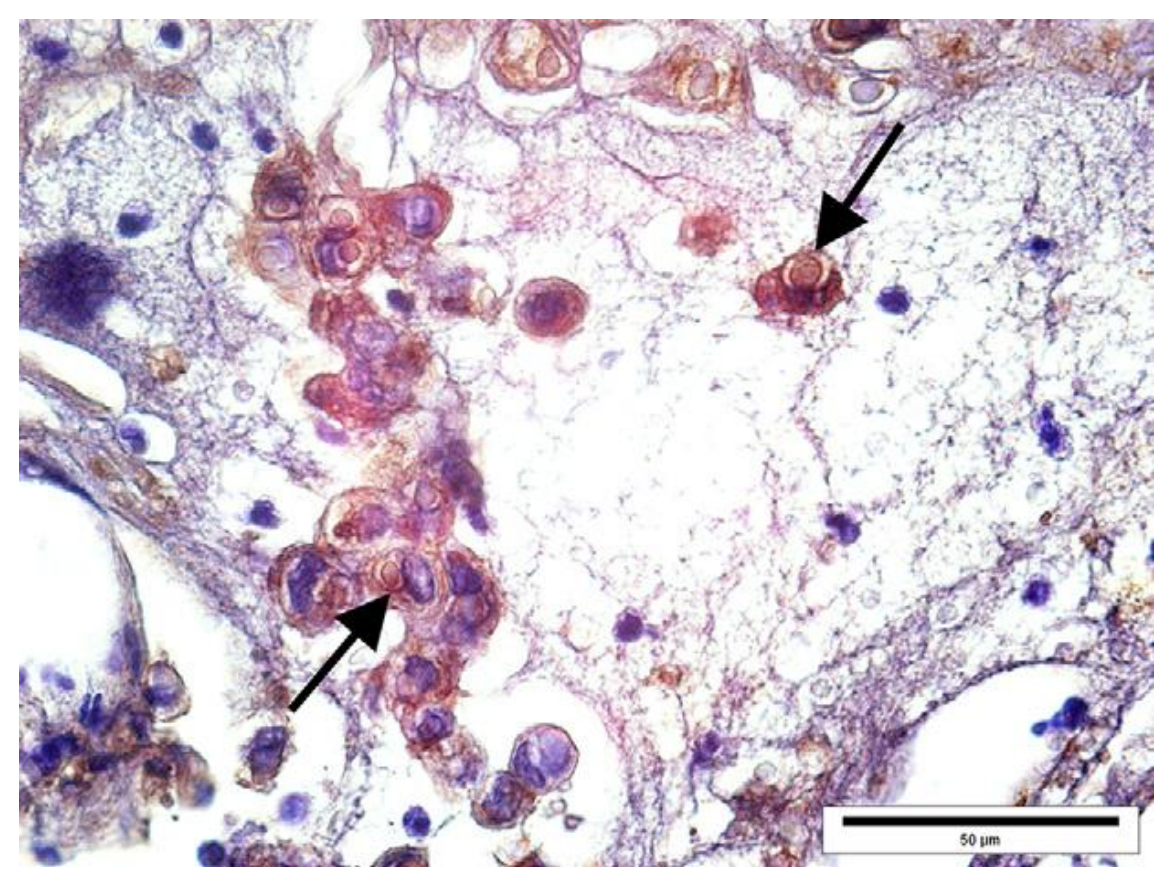


Figure 13. Virus antigen within infected basal epithelial cells of a sebaceous gland (arrows) after IN calpox infection of animal number 11. IHC. Bar, $50 \mu \mathrm{m}$.

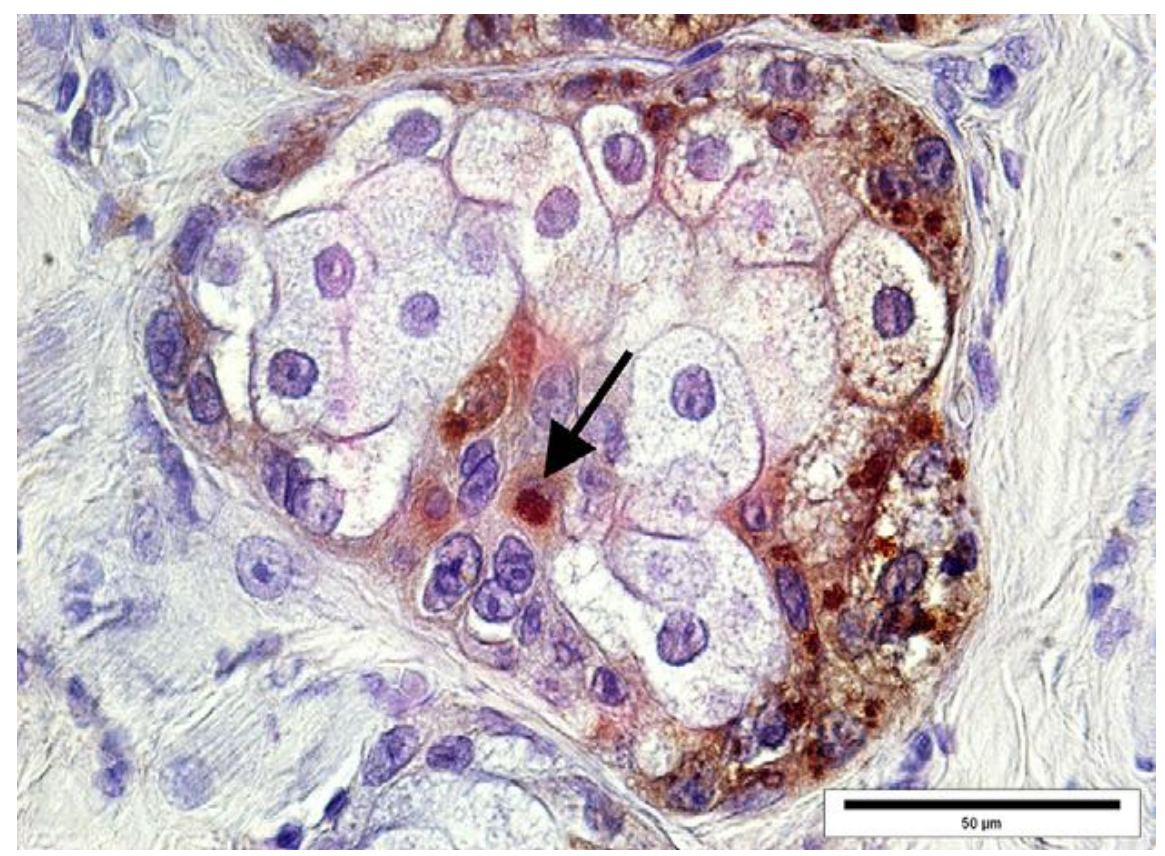

Figure 14. Intracytoplasmic inclusion bodies containing virus particles in the skin of animal number 11. TEM. Bar, $10 \mu \mathrm{m}$.

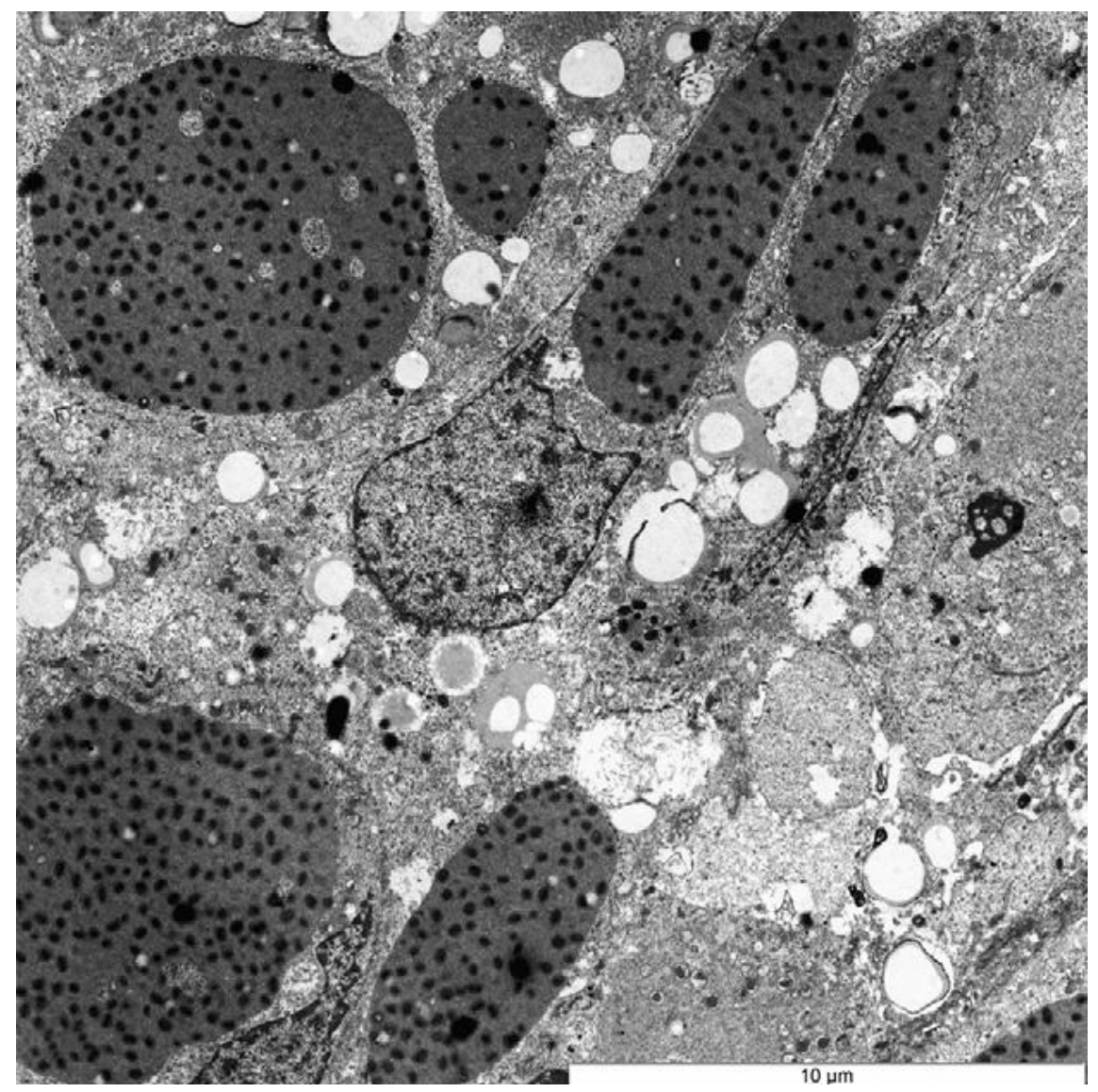


Figure 15. Higher magnification of an inclusion body releasing virus particles. Skin of animal number 11. TEM. Bar, $1 \mu \mathrm{m}$.

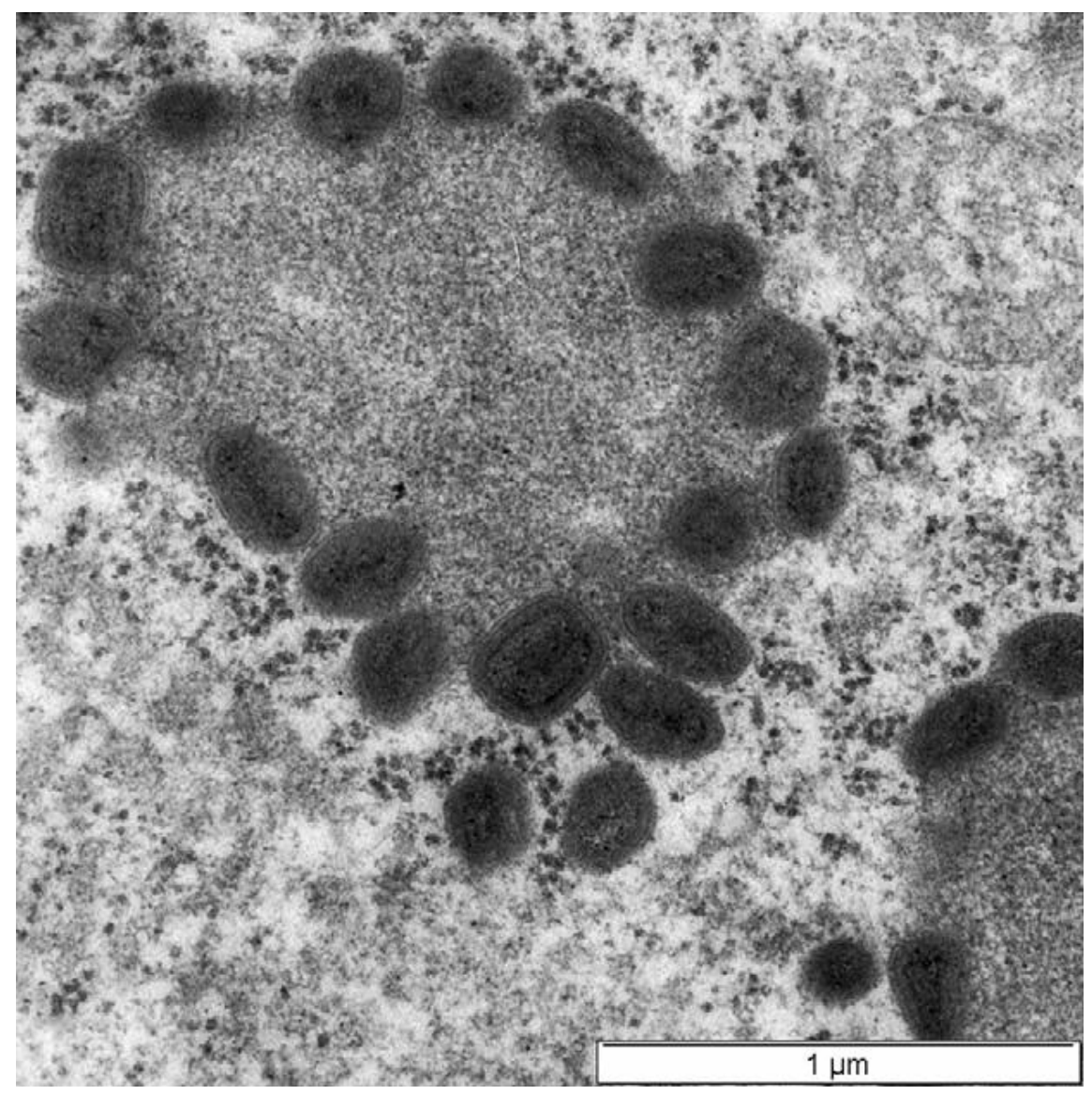

